Do Western and Eastern Europe have the same agricultural climate response? Taking adaptive capacity into account

Peer-reviewed author version

VANSCHOENWINKEL, Janka; Mendelsohn, Robert \& VAN PASSEL, Steven (2016)

Do Western and Eastern Europe have the same agricultural climate response?

Taking adaptive capacity into account. In: GLOBAL ENVIRONMENTAL

CHANGE-HUMAN AND POLICY DIMENSIONS, 41, p. 74-87.

DOI: 10.1016/j.gloenvcha.2016.09.003

Handle: http://hdl.handle.net/1942/22660 


\title{
Do Western and Eastern Europe have the same agricultural climate response? \\ Taking adaptive capacity into account
}

\author{
Janka Vanschoenwinkel \\ Doctoral School of Behavioral Sciences \& Humanities \\ Research group of environmental economics \\ Hasselt University \\ Hasselt, Belgium \\ janka.vanschoenwinkel@uhasselt.be \\ Prof. Dr. Robert Mendelsohn \\ Yale School of Forestry and Environmental Studies \\ New Haven \\ USA \\ robert.mendelsohn@yale.edu \\ Prof. Dr. Ir. Steven Van Passel \\ Research group of environmental economics \\ Hasselt University \\ University of Antwerp \\ Belgium \\ steven.vanpassel@uhasselt.be
}

Published in Global Environmental Change, November 2016

\section{Acknowledgements}

Steven Van Passel would kindly want to express his gratitude towards DG AGRI for access to the Farm Accountancy Data Network (FADN). The authors also thank the reviewers of this journal for their improvements to the final manuscript and they are grateful for the comments and suggestions they received at the conferences where this paper has been presented (IAMO forum 2015, EAAE PhD workshop 2015, Belgian PhD symposium 2015, EAERE conference 2016). Janka Vanschoenwinkel also wants to thank FWO and the doctoral schools of Hasselt University for giving a mobility grant to go to the EAAE PhD workshop in Rome. 


\begin{abstract}
Current cross-sectional methodologies measuring climate change impacts assume that regions at the same latitude face a similar climate response and therefore have the same adaptive capacity. This paper proves that assumption to be erroneous in the European Union. It does so by ameliorating the Ricardian methodology by restricting which farmers (and therefore which adaptation options) are allowed in the dataset. In doing so, a comparative Ricardian methodology is suggested that makes it possible to examine, for the first time, how the climate responsiveness of a region changes if adaptive capacity changes. The paper combines climate, soil, geographic, socio-economic, and farm-level data in a linear mixed-effect model and examines whether Eastern and Western Europe have the same climate responses and how these responses change if regional adaptive capacity increases. The paper concludes that both regions currently have a significantly different climate response, but that if Eastern Europe were to implement the same adaptation options as Western Europe, it could avoid a large decrease in land value and even benefit from climate change depending on the climate scenario.
\end{abstract}

Keywords: Adaptive Capacity; Agriculture; Climate change; Ricardian Technique; Europe JEL code: Q120, O200 


\section{Do Western and Eastern Europe have the same Agricultural Climate Response? Taking Adaptive Capacity into Account}

\section{Introduction}

It is a striking statistic that between 2011 and 2013, agricultural labor productivity in Eastern Europe was only 19 percent of agricultural labor productivity in Western Europe (EC, 2013). This is despite investment of approximately 20 billion euro of European Union (EU) and national funds to modernize Eastern European agriculture between 2000 and 2012 (Erjavec, 2012). Clearly, there continue to be sizeable socioeconomic disparities and technology gaps between Western and Eastern Europe, even though Eastern European countries entered the EU as early as 2004 (Swinnen and Vranken, 2009). In contrast with this slow transition process, the United Nations Environment Program (UNEP) points to the urgent need to close this type of technology gap in less-developed regions because climate change will have a disproportionate impact if their adaptive capacity does not increase quickly enough (IPCC, 2014d; UNEP, 2014). Indeed, "those with the least resources have the least capacity to adapt and are the most vulnerable" (p.8) (IPCC, 2001).

Nevertheless, most studies in this area have focused on the impact of climate change on agriculture in developed countries, not representing developing countries (Sanghi and Mendelsohn, 2008) or countries in transition such as those in Eastern Europe. Furthermore, studies that have looked at developing countries have ignored the technological development and steep learning curve those countries continue to face. Consequently, they are unable to distinguish climate change impacts from losses due to a lack of adaptive capacity. Although there has been a lot of criticism related to this ignorance of technological development, the criticism has failed to differentiate between (a) development due to existing technologies and knowledge in developed countries, and (b) development due to future technologies. However, in case of developing countries or countries in transition, one can already partly take into account technological development by looking at existing technologies in developed regions.

Related to this is the problem of large-scale agricultural climate change impact studies (e.g. Cline (2007)) ignoring East-West differences. In doing so, these studies assume that regions at the same latitude facing the same climate (and holding environmental and other factors fixed) have the same adaptive capacity or climate response, and thus face similar climate change impacts. This assumption is erroneous given that adaptive capacity is context-specific and differs from country to country (Smit and Wandel, 2006). In addition, adaptive capacity is not static; it changes over time. Therefore, both developed and developing countries can enhance their adaptive capabilities to cope better with climate change (IPCC, 2001). In this respect, Haddad (2005) noticed that adaptive capacity development paths in response to climate change are highly influenced by national socio-political aspirations and priorities. In the case of the European Union, it seems that the latest Common Agricultural Policy (CAP) reform is not sufficiently encouraging (Eastern European) countries to increase their rural climate change adaptive capacity. This could be due to the fact that differences in European adaptive capacity to climate change have not received significant attention, 
even though such attention is a prerequisite for understanding differences in adaptive capacities for successful targeting interventions (Vincent, 2007).

The present paper examines these warnings for the EU by separating it into Eastern and Western Europe: a region in transition and a developed region, respectively. The most recent large-scale study of climate change impacts in Europe already examined Western Europe (Van Passel et al., 2016). This paper builds on their work by testing whether Western and Eastern Europe have similar climate responses. We defined climate response using the Ricardian technique and ameliorated it in order to take into account differences in adaptive capacity. The Ricardian technique is a statistical cross-sectional regression method that measures the sensitivity of comparable land values to climate and other factors by using historical data about existing farms that face different climate and soil conditions (Mendelsohn and Dinar, 2003; Mendelsohn et al., 1994). As a result, this method takes into account hidden human, climatic, agronomic and other mechanisms that have already been presented in the regional climates (Sanghi and Mendelsohn, 2008). The main advantage of the Ricardian technique, compared to other approaches, is that it takes adaptation into account in its estimations because farmers have already adapted to the climate in which they live (Mendelsohn et al., 2009). To date, however, the methodology has never distinguished between differences in adaptive capacity within the sample examined, or how the climate responsiveness would change if adaptive capacity increases. The present paper is the first to study farmers' actual and potential climate response by estimating the same model twice, but using different datasets: the first dataset includes all Eastern and Western European farms, while the second dataset contains the same farms, but splits them in separate sub-datasets (one with only Eastern European farms and one with only Western European farms). In this way, the paper improves on the traditional Ricardian method and economically valuates the benefits of unlocking Eastern European potential adaptive capacity. As such, it provides an understanding of how climate change impacts could be moderated by increasing adaptive capacity.

Sections 2-6 discuss (2) the Ricardian technique, its assumptions and this paper's improvement; (3) the data and model estimation; (4) the empirical findings and projections of different climate scenarios; (5) the discussion; and (6) the conclusion.

\section{Methodology and modeling}

This section begins with a general overview of the Ricardian method and then clarifies how this paper's approach is different from previous studies that have assumed farm development and adaptive capacity to be the same within regions at the same latitude or climate zone.

In its original form, the Ricardian model explains variation in land value per hectare of land in different regions (Mendelsohn et al., 1994). The method assumes that land value reflects the present value of future net income for each farm (Ricardo, 1817; Seo and Mendelsohn, 2008a). Net income (NI) of the farm can be described as follows (Mendelsohn and Dinar, 2003; Wang et al., 2009):

$$
N I=\sum P_{q i} Q_{i}\left(X_{i}, L_{i}, K_{i}, C, Z, G\right)-\sum P_{x} X_{i}-\sum P_{L} L_{i}-\sum P_{K} K_{i}
$$

where $P_{q i}$ is the market price of crop i, $Q_{i}$ is the output or production function for crop $\mathrm{i}, X_{i}$ is the vector of purchased inputs for crop i, $L_{i}$ is the vector of labor for crop i, $K_{i}$ is the vector of capital, $C$ is the vector of climate variables, $Z$ is the set of soil 
characteristics, $G$ is a set of economic variables, $X_{i}$ is the vector of purchased inputs for crop i, $P_{x}$ is the vector for prices of annual inputs, $P_{L}$ is the vector for prices for labor, and $P_{K}$ is the rental price of capital.

The net present value of net income $(V)$ is as follows (Mendelsohn and Dinar, 2003; Wang et al., 2009):

$$
V=\int\left[\sum P_{q i} Q_{i}\left(X_{i}, L_{i}, K_{i}, C, Z, G\right)-\sum P_{x} X_{i}-\sum P_{L} L_{i}-\sum P_{K} K_{i}\right] e^{-\varphi t} d t
$$

where $t$ is time and $\varphi$ is the discount rate.

The Ricardian model is derived from the latter equation by assuming that each farmer maximizes net income by choosing the optimal amount of all different endogenous variables that are within his or her control $\left(Q_{i}, X_{i}, L_{i}, K_{i}\right)$ and by using land with the most suitable climate for the most profitable activity, subject to the exogenous conditions of each farm $\left(P_{q}, C, Z, G, R, P_{x}, P_{L}, P_{K}\right)$ that are outside the farmer's control (Maharjan and Joshi, 2013; Mendelsohn et al., 1994).

This profit-maximization assumption is the key to explaining how the Ricardian method takes adaptation into account: the method assumes that farmers in one location behave the same as farmers in a second location would if that second location were made to look like the first one (Lippert et al., 2009; Timmins, 2006). Referring to the example illustrated in the paper of Mendelsohn et al. (1994), this means that if a change in climate lowers the value of producing wheat, a profit maximizing farmer will adapt and switch to corn if these revenues are higher than those of wheat in the new climate.

This knowledge of how adaptation is taken into account is indispensable to understand the strengths and limitations of the model. However, it is even more important to understand which adaptation options are taken into account. The Ricardian method, which corresponds to the idea of Hedonic Pricing of environmental attributes, automatically takes into account all possible adaptation options of which data of other farmers are available in the dataset (Lippert et al., 2009). Therefore, it is the dataset on which the Climate-Response Function is based that determines the size of the adaptive capacity available per farmer. All Ricardian papers acknowledge that this implies that the methodology is very optimistic with regard to climate change adaptation because it disregards transition costs and efforts. Nonetheless, we are not aware of a Ricardian paper that tests whether the dataset or chosen sample has an influence on the result and how this would change the climate response. Still, this is important to know in case certain regions in the study have no or less access to adaptation options that are available in the dataset anyway and are thus incorrectly assumed to be at the disposal of the region.

Given that there are large differences between Eastern and Western Europe, this paper specifically tests the consistency and robustness of the European Climate-Response Function over different farmers at the same latitude and tests how the function changes if available adaptive capacity changes. This is done by comparing two models: a Single Climate-Response Model and a Double Climate-Response Model. The Single ClimateResponse Model estimates one single overarching relationship, assuming that climate coefficients are the same for both Eastern and Western Europe. This means that all the Eastern and Western European farms in the dataset are taken into account to estimate the climate response. The Double Climate-Response Model repeats the Single ClimateResponse Model, but also allows climate coefficients to vary between the two regions. This is done by multiplying a dummy for Eastern and Western Europe by each variable. This implies that the Eastern European Double Climate-Response model is based entirely 
and only on the Eastern European part of the dataset, and the Western European Double Climate-Response model is based entirely and only on the Western European part of the dataset. Therefore, the only difference between the Single and Double models is the datasets that they use. Thirdly, as an additional robustness test to further justify and test the results of the models, we applied the coefficients of the Double Climate-Response Model from one region to predict what would happen in the other region. In this way, we recognize that Eastern and Western Europe have a slightly different base climate.

In order to address the question of whether Eastern and Western Europe have the same climate response, we do not compare Eastern and Western Europe directly. Instead, we compare the Single and the Double Climate-Response Models with each other, which are identical apart from the dataset they use. If there is one consistent Climate-Response function in Europe, the Single and the Double Climate-Response Models should not be significantly different from each other. Nevertheless, for the control variables, we do compare Eastern and Western Europe directly by comparing the coefficients of the Double Climate-Response Model for each region. Finally, in order to answer the research question of how a regional Climate-Response function changes if its adaptive capacity increases, the response of one region in the Single model is compared with its own response in the Double model.

Independent of the dataset applied to the model, the profit-maximization assumption still implies that all the endogenous variables within the farmer's control are optimized and that the Ricardian model therefore only consists of a set of exogenous variables that affect the future net value of net income $\left(\mathrm{NI}^{*}\right)$, and thus land value $(V)$.

$$
\begin{gathered}
N I^{*}=f\left(P_{q}, C, Z, G, R, P_{x}, P_{L}, P_{K}\right) \\
V=\beta_{0}+\beta_{1} C+\beta_{2} C^{2}+\beta_{3} Z+\beta_{4} G
\end{gathered}
$$

These exogenous variables can be grouped in three subgroups: climate variables $(C)$, exogenous control variables $(\mathrm{Z})$ and socio-economic variables $(\mathrm{G})$. For the first subgroup, (C), we use temperature and precipitation to describe climate. These climate data are averaged into four seasons because there is a high correlation in climate data from month to month. Linear and quadric terms are introduced for both temperature and precipitation since earlier field studies proved the non-linear nature of the net revenue function (Mendelsohn and Dinar, 2003; Mendelsohn et al., 1994). Due to the quadratic climate term, the marginal impact of a climate variable $\mathrm{i}$ on the value of farmland depends upon the level of the climate, $C_{i}$, in which the farm is already located (Mendelsohn et al., 2009). Therefore, interpreting the climate coefficients should be done by interpreting the marginal effect of climate change (determined separately for precipitation $(\mathrm{p})$ and temperature $(\mathrm{t})$ ) for season $\left.\mathrm{i}\left(\mathrm{ME}_{\mathrm{i}}\right)\right)$, which is calculated as follows:

$$
M E_{i}=\frac{\partial V}{\partial C_{i}}=\beta_{1, i}+2 \beta_{2, i} C_{i}
$$

The annual average marginal effect (MEt and MEp) is derived from the previous by taking the sum of the average seasonal marginal effects. When presenting the marginal effects, we weighted the average results by a weight reflecting the total amount of farmland that each farm represents in its region. This implies that the marginal effects as presented in this paper can be interpreted as the percentage change in 1 hectare land value of a certain region associated with an increase of $1{ }^{\circ} \mathrm{C}$ in temperature for MEt or an increase of $1 \mathrm{~cm} / \mathrm{mo}$ in precipitation for MEp.

Having estimated the Ricardian model, we can calculate what the estimated value of the land under the new climate will be $\left(C_{1}\right)$ and compare this with the current climate 
$\left(C_{0}\right)$. The difference between the two is the change in welfare $(\Delta W)$ after climate has changed from $C_{0}$ to $C_{1}$ (Mendelsohn et al., 2009). GCM models can be used to calculate this non-marginal climate change impact (see section 2).

In this paper specifically, when comparing the Single and the Double ClimateResponse, above all, the marginal effects of climate have to be examined before interpreting climate change impacts from the GCM models. This is important because changes in climate are slightly different in Eastern and Western Europe. The marginal effects allow us to compare the same increase in temperature and precipitation over both Eastern and Western Europe. This allows for an interpretation of possible differences between the Single and the Double Climate-Response Models that are not related to differences in climate change. We can then draw, ceteris paribus, conclusions for climate change scenarios that differ between the regions.

Finally, land value was not only influenced by a group of climate variables, but also by a group of exogenous control variables and socio-economic variables. These are needed in order to isolate climate factors from fixed, unmeasured and climate-correlated factors (Chen et al., 2013). Because land values are used, it is necessary to account for population density, GDP per capita, elevation, and distance to ports and cities to control for market access for farm products and the opportunity cost of land utilization (Chen et al., 2013). In addition, different soil characteristics must be controlled for because these undoubtedly have an influence on productivity. Finally, since the paper is on a continental scale, it is also important to control for continental influences. A special concern in Europe is whether the EU Common Agricultural Policy (CAP) distorts climate sensitivities. Therefore, we also control for CAP subsidies at the farm level. These subsidies have a linear effect on land value because they are decoupled from production in order to reinforce market orientation and to improve environmental and social conditions (Schmid et al., 2007).

\section{Data and estimation method}

In this section we explain which data and estimation methods are used. With regard to the farm-specific data (agricultural land value, subsidies and land rented), we relied on farm accountancy data collected in 2007 by the FADN (Farm Accountancy Data Network) (FADN, 2014). FADN provides farm-specific measures of approximately 80,000 farm holdings in the EU-27, which represent nearly 14 million farms with a total utilized agricultural area of about 216 million hectares. FADN data are collected uniformly and consistently over Europe, which is important in order to correctly compare different regions. The USD-Euro exchange rate fluctuated in 2007 between 0.672 and 0.770 Euro per 1 USD (ECB, 2016).

For privacy reasons, it is not possible to link these farm holdings to unique locational coordinates, but they can be linked to the different NUTS3 (Nomenclature of Territorial Units for Statistics regions) in the EU. These are homogenous geographic units across all European countries that are identified by the EU. We used a sample of 60,563 commercial farms that utilize 5,470,490 hectare of farmland and cover by stratification 54 percent of all agricultural areas in the EU-27, situated in 1143 NUTS3 regions. Consequently, the farm sample data are clustered within different countries, which means that our dataset has a nested structure. This can lead to random effects that 
influence the variance of the dependent variable because the agricultural land values of observations in the same country may be more related to each other than to agricultural land values of observations in other countries (Crawley, 2007). Especially for this study, due to this large geographic dispersion, and given that there are multiple unmeasurable differences between Eastern and Western Europe, it is important to take into account the added variation caused by the differences between the countries. This study uses the Linear Mixed Effect Model (LME), which consists of fixed effects (that are equivalent to the Ordinary Least Squares estimates), and random country effects that make it possible to take into account differences between countries by allowing for a random shift around the intercept. This implies that the model assumes that the variation around the intercept is normally distributed for each country and with a certain variance (Zuur et al., 2009). As such, the LME model creates underlying different intercept values that capture the differences between the different countries. Alternatively, we could have used 25 country dummy variables to build a country fixed-effects model, but this would have cost 24 degrees of freedom and the results are almost identical to the results of the LME Model. This implies that national influences are captured by the model, while the paper's models still have to control for regional or individual influences on land value. The LME model is estimated by means of the Restricted Maximum Likelihood (REML). Finally, it should be noted that we can use a unique and large dataset, which has a positive influence on the robustness of the model with respect to capturing unmeasurable influences on land value.

Furthermore, the paper corrects for non-normality by taking the log transformation of the dependent variable. This is also suggested by Massetti and Mendelsohn (2011b) and Schlenker et al. (2006) since land values are log-normal. In addition, each farm is weighted using the total amount of owned agricultural land in that farm to further control for heteroskedasticity. Finally, outlier tests were conducted. The open software R was used to run the regression model and graph the results (R Core Team, 2014).

All of the information about fixed effects (climate and control variables) is linked on the NUTS3 level. The baseline climate should be representative for the recent average climate in the study region and should be of a sufficient duration to encompass a range of climatic variations (Carter and La Rovere, 2001). This study uses the 30-year normal period for temperature and precipitation from 1961-1990 from the Climatic Research Unit (CRU) CL 2.0 (New et al., 2002). These long-run climate estimates are stable.

Soil data come from the Harmonized World Soil Database, a partnership of Food and Agriculture Organization (FAO), the European Soil Bureau Network, and the Institute of Soil Science (FAO/IIASA/ISRIC/ISSCAS/JRC, 2009). Additional socioeconomic and geographic variables (population density, distance from urban areas, distance from ports, mean elevation, elevation range and GDP per capita) were obtained from EuroGeographics Natural Earth Data, the World Port Index, ESRI and Eurostat, respectively (ESRI, 2014; EuroGeographics, 2014; Eurostat, 2016; National GeospatialIntelligence Agency, 2014; Natural Earth, 2014). An overview and detailed description of all model variables and sources can be found in Appendix A. An overview of the distribution of the sampled farm land that we used can be found in Appendix B.

Once the Single and the Double Climate-Response Models had been built, we determined the marginal effects of temperature and precipitation and used Wald chisquare tests (comparable with F-tests in country fixed effects models) to compare both 
models and to test whether the climate responses of both models differ significantly. We then used the estimated parameters of the Ricardian regression to simulate impacts from future climate change. This is done based on plausible climate change scenarios. A common method to develop climate scenarios is to use the output of Global Climate Model experiments (Carter and La Rovere, 2001). To construct GCM-based climate change scenarios, an emission scenario that predicts atmospheric greenhouse gas and aerosol concentrations should be chosen (Goodess, 2014). This paper uses GCMs that are used in the AR4 and that use the well-known IPCC-approved A2 SRES scenario (Nakicenovic et al., 2000): the ECHO-G (Legutke and Voss, 1999) and NCAR PCM (Washington et al., 2000) climate models for 2071-2100. These two climate scenarios represent a moderate and a mild possible change in climate, respectively. The mean temperature and precipitation in Eastern and Western Europe of each scenario can be found in Appendix A.

Mean differences between the control climate and the future climate are calculated from these climate models (Carter and La Rovere, 2001). The standard approach in climate science literature is then to add these GCM projections of regional climate change of the control period to the subregional baseline. This method preserves subregional variation and avoids regression toward the mean is avoided (Fisher et al., 2012). Ratios (future climate/control climate) are used for temperature variables, differences (future climate minus control climate), and for precipitation variables (Carter and La Rovere, 2001). Finally, the climate generated by GCMs is attributed to each NUTS3 region centroid by interpolating the four closest grid points of the GCM scenario using inverse distance weights.

\section{Results}

This section presents the two regressions that have been modeled in this paper and introduced in section 1 (see Table 1). Both regressions consist of the same variables; however, unlike the Single Climate-Response Model, the Double Climate-Response Model allows the climate response in Europe to differ between Eastern and Western Europe. This is done by means of an interaction between each variable and a dummy indicating whether the farm is located in Western or Eastern Europe. As such, in the Double Climate-Response Model, the coefficients of Eastern Europe are estimated using the Eastern European part of the dataset, and the coefficients of Western Europe are estimated using the Western European part of the dataset. In the Single Climate-Response Model, the climate response of Eastern and Western Europe is assumed to be identical and therefore estimated using one dataset combining all Eastern and Western European farms.

Comparing both models as a whole, the ANOVA test gives a Chi square value of 2208.8, which implies a significant difference between the Single and the Double Climate-Response Models. Looking specifically at the Double Climate-Response Model, using the Wald chi-square test to determine whether the Eastern European coefficients are jointly significantly different from the Western European coefficients gives a value of 2229.2, indicating a significant difference between the two regions.

\subsection{Control variables}

For both models and regions, most of the control variables have the expected signs: higher GDP per capita, smaller distance from cities and ports, higher subsidies and 
a higher $\mathrm{pH}$ value, and a positive impact on land values. However, when comparing Western and Eastern Europe in the Double Climate-Response Model, it must be noted that subsidies do not significantly influence Eastern European land values. This could imply that subsidies have been spent on unproductive farms (Mendelsohn and Reinsborough, 2007). Furthermore, distance from cities does not have a significant impact for Eastern Europe. It should also be noted that a higher share of rented land has a negative impact on land values in Western Europe, but a positive impact in Eastern Europe. There are different and diverging explanations for this, which differ between and even within countries. In general, in Western Europe it is assumed that farmers who are owners of their agricultural land are more willing to invest in and improve their land value. However, this argument is not applicable to Belgium, for instance, where tenants are highly protected by the national land rental policy (Swinnen and Vranken, 2009). Due to the favorable rental conditions in Belgium, farmers are more inclined to rent a portion of their utilized agricultural area since it would leave them more capital for investments. Nevertheless, unlike Western Europe, renting agricultural land is established mostly in Eastern Europe for numerous reasons: for instance, imperfectly working capital markets may mean that financing of land purchases is an issue. Renting land could also prevent capital from being tied up in land that cannot be freed for investments in farm-specific assets or new technologies, and transaction costs for land sales are high (Ciaian et al., 2012). Moreover, land reforms in Eastern Europe have involved land restitutions to individuals who are not active in agriculture. Therefore, land-owners may use land for reasons other than production, such as for storing wealth or for speculative purposes. Therefore, rental markets play a key role in the exchange of land from less to more productive land users, which explains the positive sign of the coefficient for Eastern Europe. With respect to soil type, gravel, silt and sandy soils tend to be slightly harmful in Western Europe, but beneficial in Eastern Europe. As expected, a location at a higher altitude has a positive impact on land values as well. Finally, with respect to the random effects, there are two sources of random variation: one between countries, and one for farms within a country (Larget, 2007). The variance for the random intercept is $\left(1.150^{2}\right)$ 1.323 for Western Europe and $\left(0.835^{2}\right) 0.697$ for Eastern Europe. This explains how much variability there is between farms over all countries. This means that the average relationship can be shifted for each country by something that is normally distributed with a variance of 1.323 for Western Europe and 0.697 for Eastern Europe. When comparing the variance of Eastern and Western Europe, it can be seen that the differences between farms in Eastern European countries is smaller because their variance is smaller. On the other hand, the residual variance is (4.8752) 23.763 for Western Europe and (5.0272) 25.273 for Eastern Europe. This explains the amount of variability there is within the different countries. In this case, it can be seen that within distances between farmers are larger in Eastern European countries than in Western European countries.

\subsection{Climate variables}

The variables of key interest for this paper are the climate variables. It is clear from column D of Table 1 that it is fundamentally wrong to assume that farmers in Western Europe behave the same as farmers at the same latitude in Eastern Europe. Twenty-two of the 31 variables, 10 of which are climate variables, differ significantly between Eastern and Western Europe. The Wald chi-square test confirms that all the temperature variables $($ Chisq $=528.65)$, and all the precipitation values $($ Chisq $=371.89)$, 
and all the precipitation and temperature variables combined (Chisq $=880.91$ ), jointly differ significantly each time at the 1 percent level between Eastern and Western Europe. Clearly, there is (currently) no such thing as a European response to climate change and it is crucial to acknowledge this when applying the Ricardian method to the model.

Therefore, we look in more detail below at the direction of the differences between the traditional Single Climate-Response Function, which does not sufficiently acknowledge differences between farmers at the same latitude, and the Double ClimateResponse Function, which distinguishes clearly between regions at the same latitude. This means for Western Europe, comparing column A with column C, and for Eastern Europe comparing column A with column B from Table 1. Starting with Western Europe, it can be concluded that, when comparing the Single and the Double Climate-Response, there is no significant difference for the Western European region between the two models. For Eastern Europe, however, these conclusions cannot be drawn: comparing the Eastern European Single Climate-Response with its Double Climate-Response indicates that the Double Climate-Response is more volatile than the Single Climate-Response.

These two findings are confirmed when looking at Table 2 and Table 3. Table 2 presents the average regional marginal temperature and precipitation effects on land value for Eastern and Western Europe. It shows the percentage change in land value when temperature increases by $1^{\circ} \mathrm{C}$, or when precipitation increases with $1 \mathrm{~cm}$ per season. Independent of the model chosen, both regions suffer from increases in summer temperatures. This is because warmer summers stress crops and livestock, while warmer springs are beneficial since they lengthen the growing seasons. However, even though the direction of the response is the same, it is clear that the Eastern European response is more volatile in the Double Climate-Response Model than in the Single ClimateResponse Model, while for Western Europe both models give very similar results.

However, interpreting the average MEt (Table 2) does not provide a good view on the climate response of the different countries because it does not show the within differences (the high positive impacts of the Northern countries (Estonia, Latvia, and Lithuania) averages out the negative impacts of the Southern regions). In Table 3, on the other hand, both the MEt and MEp for the Double and the Single Climate-Response are presented, together with a ranking from the lowest marginal effect (1) to the highest marginal effect. These results are also visualized at NUTS3 level for the annual marginal effect of temperature in Figure 1a. With regard to Western Europe (both the Single and the Double Climate-Response Models), the marginal effects lie relatively close to each other. In the Double Climate-Response Model for Eastern Europe the Northern countries (Estonia, Latvia and Lithuania) enjoy significantly higher benefits from an increase in temperature than in the Single Climate-Response Model. These differences decrease in the Single Climate-Response Model and the impacts lie closer together.

Therefore, Table 3 and Figure 1a clearly confirm our findings from Table 1. Looking at the Single Climate-Response Model, the marginal impacts of climate in Eastern and Western Europe are very similar to each other. However, when looking at the Double Climate-Response Model, the two regions behave quite differently: Western Europe responds similar to climate change as in the Single model, while Eastern European countries face a more negative impact than in the Single Climate-Response Model.

Finally, the above results show that individual differences between countries need 
to be taken into account as well since marginal climate effects differ over Europe because of differing initial conditions. Therefore, we have verified that the base climate, which slightly differs in both regions, does not influence the marginal impacts. Using the Western European coefficients of the Double Climate-Response Model to predict what would happen in the Eastern European climate shows that Eastern Europe would react in a similar way to how Western Europe would. Both the marginal impact of temperature (14.05 percent) and precipitation (12 percent) increase in Eastern Europe when the Western European coefficients are used. For Western Europe, on the other hand, if the climate response of Eastern Europe (in the Double Climate-Response Model) is applied to the Western European climate, the marginal effect of temperature and precipitation both decrease. Comparing the marginal effect of Eastern Europe in the Single ClimateResponse Model (13.6 percent) and the marginal effect of Eastern Europe when the climate response of Western Europe in the Double Climate-Response Model is used (14.05 percent) highlights the fact that the base climate is not causing significant bias to the previous conclusions.

\subsection{Future welfare changes}

Having proven that the Single and the Double Climate-Response Model differ significantly from each other and give different climate impacts under the same increase in temperature and precipitation, we now examine how these climate impacts change when GCM-based climate change scenarios are applied to the models. Using the NCAR PCM (mild climate change) and the ECHO-G (moderate climate change) scenario, this section determines for each of the regressions the new land value after climate change has taken place according to each scenario. Table 4 displays the percentage differences between the future land value estimates and the current climate estimates for each type of this paper's regressions. This is also visualized in Figures $1 \mathrm{~b}$ and 1c.

In the NCAR PCM scenario, precipitation increases on average by $1.2 \mathrm{~mm}$ per year, and temperature increases by $3.1^{\circ} \mathrm{C}$ per year in Eastern Europe. In Western Europe, temperature increases on average by $2.8^{\circ} \mathrm{C}$ and precipitation decreases by $0.2 \mathrm{~mm}$ per year. Comparing the Single and the Double Climate-Response, it is clear that the same climate change scenario causes a more negative impact in Eastern Europe in the Double Climate-Response Model than in the Single Climate-Response Model. For Western Europe, decreases in land value are slightly under 0 percent depending on which regression is taken, but there is no significant difference between both models.

If the ECHOG scenario would occur, average increase in rainfall would be 0.6 mm less than in the NCAR PCM scenario, while the temperature increases by an additional $1.6{ }^{\circ} \mathrm{C}$. For Western Europe, on the other hand, total rainfall decreases by 1.3 $\mathrm{mm}$ and temperature increases by $4.11^{\circ} \mathrm{C}$ compared to the current climate. Land values in Western Europe would decrease by about 32 percent, independent of which regression is taken. For Eastern Europe, the same conclusions can be drawn as in the NCAR PCM scenario: if the Single Climate-Response is assumed to be the correct one, Eastern Europe benefits on average from climate. Otherwise, it faces decreases in land value of up to 47 percent.

Therefore, the same change in climate in Eastern Europe causes significantly different impacts under both models. As such, it can be concluded that under the Single Climate-Response Model, Eastern Europe is better off than under the Double ClimateResponse Model. 


\section{Discussion}

The impacts determined by the Single and the Double Climate-Response Model clearly differ significantly between Western and Eastern Europe. Therefore, there is (currently) no common European climate response. Firstly, this raises two questions: what explains the differences between the two models, and which of the two models should be used for further studies.

The difference between the Single and the Double Climate-Response Models is explained by the differences in datasets that they used. This is because the Ricardian technique only accounts for adaptation options that are observed in the dataset. For the Double Climate-Response Model, the paper allowed the model parameters to differ between Eastern and Western Europe. Therefore, the model looks independently at Eastern and Western Europe, which means that for each region there is one inventory of potential adaptation options, each with the technologies and knowledge of that region. Since the variation in Eastern European farms is smaller, and since agriculture is less developed, modernized, and capital-intensive than in Western Europe, the inventory of potential Eastern European adaptation options is smaller in the Double Climate-Response Model than in the Single Climate-Response Model. This is undoubtedly caused by institutional and societal differences that influence the development options of regional agriculture. Therefore, the negative impact of climate change is overestimated in the Double Climate-Response Model because multiple plausible adaptation options, which already exist in Western Europe, are not taken into account. Moreover, after unifying with the European Union, Eastern European countries are continuing to re-adjust their institutions according to Western European templates and Eastern European farmers have access to EU farm subsidies.

As such, looking at the Single Climate-Response Model, where all coefficients are assumed to be identical for Eastern and Western Europe, implies looking at a model that assumes the convergence of Eastern Europe to the Western European societal, economic, political and institutional model has been completed. Therefore, in the Single ClimateResponse Model, the adaptive capacity of Eastern Europe is much larger because plausible adaptation options available in Western Europe are assumed to be as well available in the adaptation inventory of Eastern Europe. Consequently, the Single Climate-Response Model looks at one combined inventory of potential adaptation options of both Western and Eastern Europe together. However, this is overly optimistic at the moment because before Eastern Europe gains access to the same level and quantity of adaptation options as Western Europe, complex behavioral, technical, societal and institutional costs and adjustments at all levels of the society are required (Downing et al., 1997; Tol et al., 2004). Such a transformation cannot take place overnight and it is not clear how long the convergence process will take. Nevertheless, the Ricardian model, when taking adaptation into account, only assumes optimal autonomous adaptation at the local, farm-scale level, without looking at the broader contexts (such as agricultural and trade policies, policy intervention) or acknowledging the dynamic processes needed to go from the current equilibrium to the new equilibrium (Kelly et al., 2005; Lippert et al., 2009; Polsky and Easterling III, 2001). This observation is key to correctly interpreting and using the results of this study.

\subsection{Policy implications}

Ultimately, both models should be looked at simultaneously on a resilience scale 
from the current Double Climate-Response where Eastern Europe has a significantly lower adaptive capacity, to the most optimal Single Climate-Response where Eastern Europe benefits from the same adaptive capacity as Western Europe. As such, the Double Climate-Response Model represents the case in which there is no adaptation transfer from Western Europe to Eastern Europe and it is clearly the most pessimistic model on the resilience scale. Therefore, the adaptive capacity in the Double Climate-Response Model can be defined as independent and autonomous profit-maximizing farm behavior. On the other hand, the Single Climate-Response Model represents the most optimistic model on the resilience scale. This model represents the currently locked, potential adaptive capacity of Eastern Europe, which only becomes available if Eastern Europe is capable of implementing Western European adaptation technologies and the necessary accompanying institutional transformation.

One of the plausible reasons why adaptation is currently more difficult in Eastern Europe than in Western Europe can be found in the currently already existing adaptation deficit that most of these countries are facing regarding the current climate (Fay et al., 2010). Comparing gross value added or crop yield per farm across the EU-27 shows that most Eastern European farms are still not yet obtaining the yields they could potentially achieve (Giannakis and Bruggeman, 2015; Supit et al., 2010). This can be explained by the passed centralized input-focused over-specialization, which has "left the sector unprepared to adapt to knowledge-based farming better suited to a world of constrained resources” (p.110) (Fay et al., 2010). While market principles are now predominant all over the European Union, and while Eastern Europe made a lot of progress to close the gaps, the countries in this region continue to face significant socio-economic setbacks that decrease the countries' options to respond to the current and the future climate.

Nevertheless, yields, economic performance, competitiveness, and thus the adaptive capacity of agriculture can be increased by increasing levels of gross fixed capital formation (GFCF). The GFCF measurement indicates how much of the value added in agriculture is invested rather than consumed (European Commision, 2014). In 2011, 90 percent of the EU-28 gross value added was invested in the EU-15 and some of the lowest levels of agricultural investment could be found in Eastern European countries (European Commision, 2014). In addition, over the last years (although this is now changing with the 2013 CAP reform), CAP direct payments per farm holding and even per hectare were also significantly lower for Eastern European farms than for Western European farms. Therefore, it seems that there is also a gap between support needed and support received.

As a conclusion for policy measures, the results of this paper imply that the importance of a large adaptive capacity on all possible fields (crop variety, technological efficiency, institutional fundamentals, sustainable farm management, different farm types, etc.) in order to tackle climate change impacts cannot be overestimated. However, it takes time to increase adaptive capacity, while the effects of climate change are already becoming visible. Therefore, financial means and other institutional support with regard to knowledge transfer and implementation management are necessary in order to improve adaptive capacity. However, different farmers (big versus small, crop versus livestock, specialized versus mixed farms, location, etc.) are affected differently by climate change and require adapted support. Therefore, it is important to conduct further studies on the country or small region level to determine specifically which types of farms are the most 
vulnerable and to determine the exact type of support they each need. Currently, only a few studies have examined climate change on the individual country level in Eastern Europe.

Given the current development efforts of Eastern Europe, and if further significant institutional efforts are continued, we believe there is no reason to believe that the assumptions of the Double Climate-Response Model will hold in the future. However, before the Single Climate-Response Model becomes reality, significant transition costs are necessary before equal adjustment and adaptation conditions are achieved over all regions. These costs are not taken into account by the Ricardian Technique because it only measures long-term effects, ignoring the period between the short and the long term. The results of the Double Climate-Response Model provide an initial idea of the benefits of such transition costs and should encourage all stakeholders to make the effort to further increase adaptive capacity in Eastern Europe.

5.2 Methodology

Comparing the two models has provided a better understanding of the benefits of increasing adaptive capacity and an economic valuation for unlocking Eastern European potential adaptive capacity. Future Ricardian studies should examine how to further improve this two-model framework. First of all, not all regions have the situation where a developed region is located near a region in transition or in development. A research suggestion here could be to use traditional crop models or experimental simulations to test how more-developed technologies would behave in these less-developed environments. The results of these experimental simulations could be used to build a dataset with a higher adaptive capacity, which could be used to test how the climate response changes if a higher adaptive capacity is available. In a similar way, combining experimental simulations and cross-sectional methods could also be the solution to take into account future technological improvements. This paper has only been able to take into account existing technologies to model technological development in Eastern Europe. However, future technologies might increase adaptive capacity even more. By means of experimental simulations, the dataset could be enlarged with more technologies than are (currently) available in Europe alone, and so different Ricardian models can be estimated with different adaptive capacities. Further applications of this comparative Ricardian modeling should also elicit and visualize which adaptation options are included in the unused adaptive capacity. Finally, to further test the framework of the resilience scale from the Double to the Single Climate-Response Model presented in this paper, this study should be repeated after 5-10 years in order to identify the direction in which Eastern Europe is moving.

All of this is important because many climate change studies have already created before-and-after pictures of the impact of climate change. What is of interest for policy now is to picture the dynamic path in between those two stages (Mendelsohn, 2007). The present paper is a clear step towards comparing how different decisions with regard to adaptation options included in the dataset influence regional climate responsiveness. There is an urgent need to improve methods in this direction.

With regard to the correctness of these conclusions, a number of points reinforce this paper's conclusion. First of all, the models are fairly robust. This can be seen by looking at the Western European coefficients and marginal impacts over both models: the Western European climate response is almost the same in both the Single and the Double 
Climate-Response Models. In the Double Climate-Response Model, Western Europe relies on its own adaptive capacity (because the coefficients are determined only on the Western European dataset). Nevertheless, Western Europe responds approximately the same as it does in the Single Climate-Response model, where it can also rely on the adaptive capacity of Eastern Europe. This proves that the adaptive capacity of Western Europe is not significantly increased if the adaptive capacity of Eastern Europe is added. On the other hand, this is the case for Eastern Europe. If the adaptive capacity of Western Europe is added to the adaptive capacity of Eastern Europe, that region will respond more positively to changes in climate. This conclusion is also confirmed by looking at the variance for the random intercept of the LME Model, where it can be seen that there are fewer differences between Eastern European countries. With regard to their adaptive capacity, this means that farmers can rely less on adaptation knowledge and technologies from more Southern countries.

Secondly, as with all models, the correctness of the model depends on how well it can control for unmeasurable influences. This paper's large dataset enables the LME Model to correct for national influences. One of the ways we tested this was by adding a national variable of which regional data were available (farm taxes- Results can be provided by the author on request). This brought no significant influence to the models, indicating that the national influence is well captured by the LME model. Also, in Appendix C, comparison with a standard country fixed effect model and an LME model estimated with ML estimation is shown for the Double model, indicating its robustness. However, in the event that there is an influence other than adaptive capacity that the paper does not control sufficiently for, it should be highlighted that the paper's conclusions are only based on the comparison of two identical models. The only thing that differs between the models is the dataset upon which they are based. This also implies that potential bias is (at least partially) cancelled out when evaluating the differences. The best way to prove this would be to add (endogenous) variables that indicate differences in adaptive capacity. If this is successfully controlled for, the climate response of the Double and the Single Model should move together.

Thirdly, while we started by comparing the marginal effects of both models to examine the impact of the same increase in temperature and precipitation, we also verified that the base climate, which slightly differs in both regions, does not influence the conclusion.

Therefore, this paper offers a solution for one limitation of the Ricardian Method. However, when interpreting the results, readers should still keep in mind other limitations of the method. The method specifies climate as a combination of temperature and precipitation, while disregarding carbon dioxide concentrations and extreme weather events. Also, with regard to predictions for 2100, it assumes that apart from climate and adaptive capacity, all other factors remain constant. This is done in order to see the effect of change in climate and adaptive capacity, ceteris paribus, on climate change impacts. However, Eastern Europe, which is a transition economy, is likely to face changes in land value and prices as productivity increases and as Eastern Europe grows towards Western Europe. Transition costs, for instance, will probably be significant, even though they are also not taken into account by the methodology. Moreover, future predictions of benefits and damages from climate change may be overestimated because if production falls, prices will rise and vice versa. However, it is difficult to project how prices will behave 
in the European Union because of changing global and regional policies, increasing world population and changing food preferences.

\section{Conclusion}

This study traces back the concern of whether climate impact estimates are consistent and robust over space to the question whether policy, institutes, society, and behavior are capable of bringing forth equal and optimal adjustment conditions over the entire region studied. Using a comparative continental scale - Ricardian analysis - and acknowledging its assumption of autonomous farm adaptation behavior, we warn that underlying adaptation requirements are not necessarily realistically applicable to all regions in the dataset.

Therefore, with respect to the methodology and further applications, this paper shows the benefits of testing farm systems in developing regions or transition economies with reference to those of more developed regions with comparable climate variations. It does so by ameliorating the Ricardian methodology by restricting which farmers (and therefore which adaptation options) are allowed in the dataset. As such, we have modeled both a Single Climate-Response Model (implying that two regions have the same adaptive capacity) and a Double Climate-Response Model, which examines the adaptive capacity of two regions separately (without assuming there is a transfer in adaptation inventory and knowledge). The comparison between the two climate response functions identifies unused adaptive capacity enlargement options and provides insights into the economic value of these potential enlargement options. Further applications of this comparative Ricardian modeling should elicit and visualize which adaptation options are included in the unused adaptive capacity and how this translates to region- and farmspecific policy.

With respect to the European case study, this paper mostly improves understanding on the differences between Eastern and Western Europe in impacts and associated costs of climate change. It shows that the region with the lowest adaptive capacity, Eastern Europe, suffers the most from climate change. However, if Eastern Europe were to apply the same adaptation options as Western Europe, it would avoid a significant decrease in land value, or even benefit from climate change, depending on the climate scenario. Since it is unrealistic to assume that this will occur by counting on autonomous, profit-maximizing or market-driven farm behavior, we justify the need for planned adaptation in Eastern Europe. The European Union, the CAP, national governments and regional policy must attempt to overcome the barriers to adaptation in Eastern Europe and increase Eastern European adaptive capacity by providing more information on adaptation opportunities and climate change, by enlarging the adaptation options and resource inventory and by creating a favorable implementation and management environment, by encouraging knowledge and skills transfer between all European farmers and by guiding farmers in making efficient adaptation decisions. 


\begin{tabular}{|c|c|c|c|c|c|c|c|c|c|}
\hline & Variable & Description & Units & Mean East & Mean West & Min & Max & Sd & Source \\
\hline \multirow{6}{*}{ 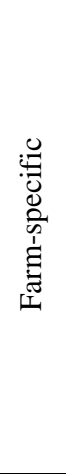 } & $\begin{array}{l}\text { Agricultural land } \\
\text { value }\end{array}$ & $\begin{array}{l}\text { Valued on the basis of prices (net of acquisition costs) that apply in the region for } \\
\text { non-rented land of similar situation and quality sold for agricultural purposes. The } \\
\text { replacement value is divided by the amount of land owned. }\end{array}$ & $€ /$ ha & 1419.45 & $15,817.71$ & 50.00 & 621,900 & $22,937.03$ & FADN \\
\hline & Land owned & Land in the owner's occupation and land in share-cropping & ha & 40.58 & 37.37 & 1.00 & 4739.00 & 94.43 & FADN \\
\hline & UAA & $\begin{array}{l}\text { Utilized agricultural area consists of land in owner occupation, rented land, land in } \\
\text { share-cropping. }\end{array}$ & ha & 118.47 & 78.20 & 1.00 & 9808.00 & 262.52 & FADN \\
\hline & Farms represented & Sum of weighting coefficients of individual holdings in the sample. & number & 89.43 & 56.77 & 1.00 & 10550 & 243.76 & FADN \\
\hline & Subsidies & Subsidies on current operations linked to production (not investments) per UAA & $€ /$ ha & 227.80 & 430.70 & 0.00 & 4981.00 & 390.59 & FADN \\
\hline & Share rented land & Total leased land out of the total utilized agricultural land. & ha/ha & 0.30 & 0.33 & 0.00 & 1.00 & 0.33 & FADN \\
\hline \multirow{5}{*}{$\overline{\bar{b}}$} & Gravel & Volume \% gravel (materials in a soil larger than $2 \mathrm{~mm}$ ) in the topsoil & $\%$ vol & 6.51 & 9.19 & 2.44 & 18.35 & 2.77 & World Soil database \\
\hline & Sand & Weight \% sand content in the topsoil & $\% w t$ & 27.64 & 31.53 & 10.83 & 45.93 & 6.45 & World Soil database \\
\hline & Silt & Weight $\%$ silt content in the topsoil & $\% w t$ & 52.39 & 46.28 & 18.19 & 83.02 & 10.54 & World Soil database \\
\hline & Clay & Weight \% clay content in the topsoil & $\% w t$ & 19.93 & 21.3 & 5.80 & 44.53 & 5.00 & World Soil database \\
\hline & $\mathrm{pH}$ & pH measured in a soil-water solution & & 5.99 & 6.28 & 4.18 & 7.88 & 0.65 & World Soil database \\
\hline \multirow{7}{*}{ 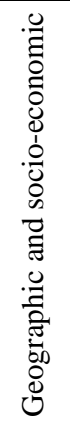 } & Distance to cities & Distance from cities with population $>500,000$ & $\mathrm{~km}$ & 101.73 & 115.23 & 0.00 & 843.00 & 73.80 & Natural Earth data \\
\hline & Distance to ports & Distance from medium and large ports & $\mathrm{km}$ & 268.59 & 162.67 & 0.00 & 636.20 & 130.30 & World port index \\
\hline & Elevation mean & Elevation mean & $\mathrm{m}$ & 199.50 & 382.54 & 0.00 & 2092.00 & 301.30 & ESRI \\
\hline & Elevation range & Elevation range & $\mathrm{m}$ & 441.63 & 1145.45 & 1.00 & 4255.00 & 869.60 & ESRI \\
\hline & GDP & Gross domestic product per capita & $€ /$ cap & 7068 & 24654 & 2.10 & 78.00 & 11.18 & Eurostat \\
\hline & Freight transport & $\begin{array}{l}\text { National annual road freight transport by regions of loading (1000 tonnes - total } \\
\text { transported goods) }\end{array}$ & tonnes & 2628 & 5508 & 0.00 & 162.10 & 7.12 & Eurostat \\
\hline & Population density & Population density in 2010 & cap $/ \mathrm{km}^{2}$ & 98.50 & 156.13 & 2.00 & 2883.00 & 189.66 & $\begin{array}{l}\text { ESRI, MBR, and } \\
\text { EuroGeographics }\end{array}$ \\
\hline
\end{tabular}

Summary of climate variables

\begin{tabular}{|c|c|c|c|c|c|c|c|c|c|c|c|c|c|c|c|}
\hline & \multicolumn{3}{|c|}{ Winter } & \multicolumn{3}{|c|}{ Spring } & \multicolumn{3}{|c|}{ Summer } & \multicolumn{3}{|c|}{ Autumn } & \multicolumn{3}{|c|}{ Annual } \\
\hline & CURRENT & NCAR PCM & ECHO-G & CURRENT & NCAR PCM & ECHO-G & CURRENT & NCAR PCM & ECHO-G & CURRENT & NCAR PCM & ECHO-G & CURRENT & NCAR PCM & ECHO-G \\
\hline Precipitation West & 6.9 & 7.2 & 7.4 & 6 & 6.4 & 5.6 & 5.6 & 5.2 & 4.4 & 7.2 & 6.7 & 6.9 & 25.7 & 25.5 & 24.4 \\
\hline Precipitation East & 3.7 & 4.4 & 4.4 & 4.7 & 5.8 & 5.1 & 7.4 & 7.2 & 6.9 & 4.8 & 4.5 & 4.9 & 20.7 & 21.9 & 21.3 \\
\hline Temperature West & 3.5 & 6.4 & 7.1 & 9.3 & 11.7 & 12.8 & 18 & 20.6 & 22.7 & 11.4 & 14.5 & 15.9 & 10.5 & 13.3 & 14.6 \\
\hline Temperature East & -1.8 & 2.3 & 3.6 & 8.1 & 10.6 & 12.4 & 17.5 & 20.2 & 21.8 & 8.9 & 12.2 & 13.8 & 8.2 & 11.3 & 12.9 \\
\hline
\end{tabular}




\begin{tabular}{lrrr}
\hline Country & UAA & UAA owned & Land represented \\
\hline Bulgaria & 111,200 & 14,477 & $1,322,985$ \\
Czech Republic & 643,471 & 58,183 & $2,936,164$ \\
Estonia & 118,143 & 42,211 & 851,698 \\
Hungary & 162,639 & 75,703 & $2,563,471$ \\
Lithuania & 175,466 & 49,330 & $1,951,138$ \\
Latvia & 192,106 & 82,295 & $1,300,086$ \\
Poland & 435,538 & 284,297 & $12,404,944$ \\
Romania & 192,326 & 130,987 & $6,210,678$ \\
Slovenia & 14,617 & 7,673 & 465,960 \\
Slovakia & 155,401 & 8,777 & 599,898 \\
\hline East & $2,200,908$ & 753,932 & $30,607,023$ \\
\hline
\end{tabular}

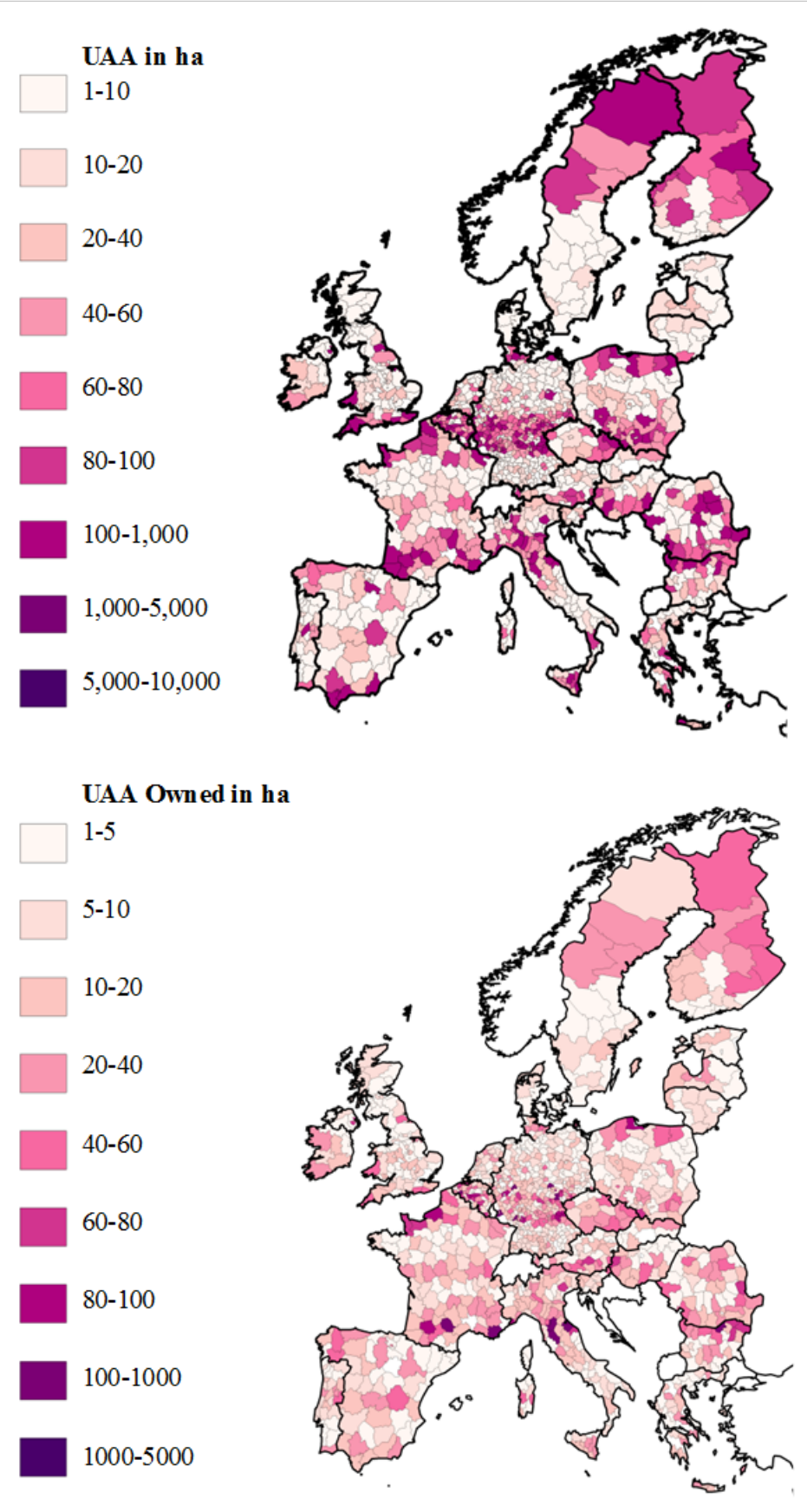

\begin{tabular}{lrrr} 
Country & UAA & UAA owned & Land represented \\
\hline Austria & 77,906 & 50,797 & $2,423,340$ \\
Belgium & 47,478 & 13,714 & $1,163,564$ \\
Denmark & $1,164,091$ & 256,210 & $13,832,557$ \\
Finland & 213,474 & 150,156 & $2,291,069$ \\
France & 345,511 & 250,590 & $18,026,483$ \\
Germany & 54,296 & 34,471 & $1,977,304$ \\
Greece & 273,808 & 73,850 & $12,596,828$ \\
Ireland & 37,625 & 17,070 & $2,851,355$ \\
Italy & 63,316 & 51,414 & $4,722,952$ \\
Luxembourg & 412,512 & 275,067 & $10,286,832$ \\
Netherlands & 42,346 & 20,448 & 129,084 \\
Portugal & 49,136 & 30,429 & $1,730,903$ \\
Spain & 40,428 & 33,208 & $1,615,103$ \\
Sweden & 82,051 & 47,104 & $1,938,570$ \\
United Kingdom & 365,603 & 256,132 & $10,150,824$ \\
\hline West & $3,269,582$ & $1,560,658$ & $85,736,765$ \\
\hline
\end{tabular}

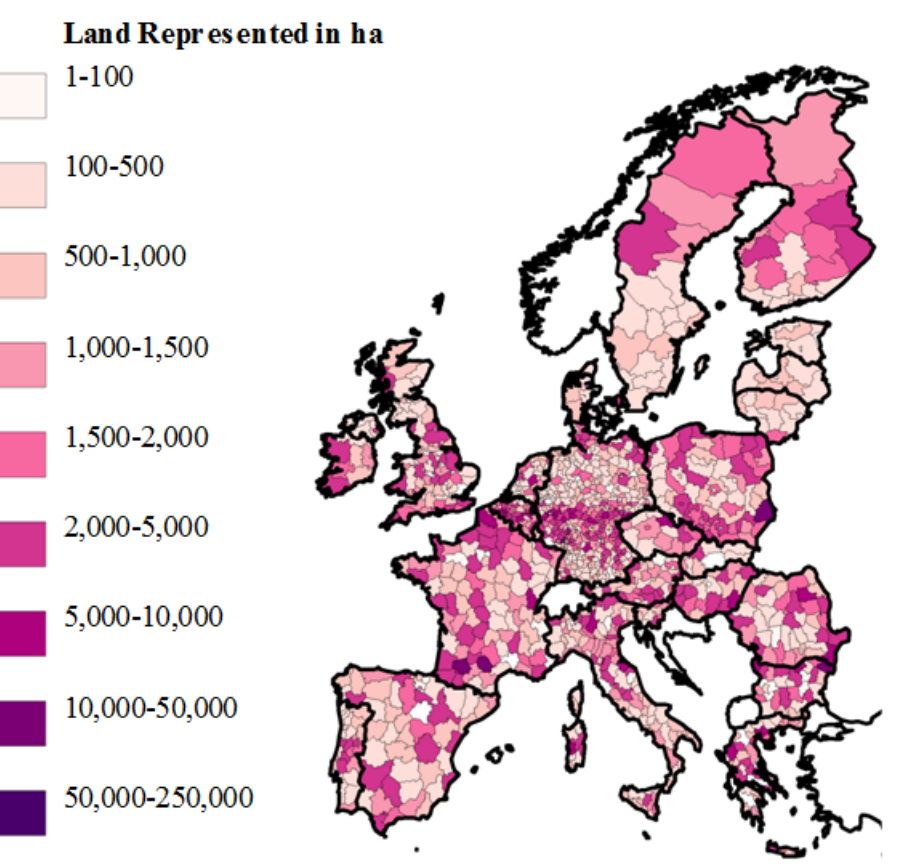


Table 1: Single and Double Climate-Response Mixed Effect Regressions

\begin{tabular}{|c|c|c|c|c|c|c|c|c|c|c|}
\hline \multirow[b]{4}{*}{ (Intercept) } & \multicolumn{3}{|c|}{ Single } & \multicolumn{7}{|c|}{ Double Climate-Response } \\
\hline & \multicolumn{3}{|c|}{ a) East + West } & \multicolumn{3}{|c|}{ b) East } & \multicolumn{3}{|c|}{ c) West } & d) Difference \\
\hline & Estima & & Std.Error & Estima & & Std.Error & Estima & & Std.Error & Estimate \\
\hline & -0.822 & & 0.524 & -0.966 & & 2.331 & 2.955 & & 2.398 & 3.921 \\
\hline Temp. Winter & -0.010 & & 0.017 & -0.511 & $* * *$ & 0.049 & -0.017 & & 0.021 & $0.494^{* * *}$ \\
\hline Temp. Winter Squared & 0.002 & $*$ & 0.001 & -0.021 & $* *$ & 0.009 & 0.006 & $* * *$ & 0.001 & $0.027^{* * *}$ \\
\hline Temp. Spring & 0.223 & $* * *$ & 0.033 & 1.565 & $* * *$ & 0.141 & 0.082 & $*$ & 0.044 & $-1.484^{* * *}$ \\
\hline Temp. Spring Squared & 0.018 & $* * *$ & 0.002 & -0.054 & $* * *$ & 0.009 & 0.025 & $* * *$ & 0.002 & $0.079^{* * *}$ \\
\hline Temp. Summer & 0.414 & $* * *$ & 0.061 & -2.143 & $* * *$ & 0.349 & 0.446 & $* * *$ & 0.075 & $2.589^{* * *}$ \\
\hline Temp. Summer Squared & -0.019 & $* * *$ & 0.002 & 0.043 & $* * *$ & 0.010 & -0.018 & $* * *$ & 0.002 & $-0.06^{* * *}$ \\
\hline Temp. Autumn & 0.144 & $* *$ & 0.060 & 1.065 & $* * *$ & 0.304 & 0.338 & $* * *$ & 0.069 & $-0.727^{* *}$ \\
\hline Temp. Autumn Squared & -0.015 & $* * *$ & 0.003 & -0.031 & $* *$ & 0.015 & -0.026 & $* * *$ & 0.003 & 0.005 \\
\hline Precip. Winter & 0.055 & $* * *$ & 0.015 & -0.026 & & 0.116 & 0.110 & $* * *$ & 0.016 & 0.136 \\
\hline Precip. Winter Squared & 0.001 & & 0.001 & 0.017 & & 0.013 & 0.000 & & 0.001 & -0.017 \\
\hline Precip. Spring & -0.218 & $* * *$ & 0.025 & -0.197 & & 0.136 & -0.202 & $* * *$ & 0.029 & -0.005 \\
\hline Precip. Spring Squared & 0.008 & $* * *$ & 0.001 & -0.006 & & 0.012 & 0.006 & $* * *$ & 0.002 & 0.012 \\
\hline Precip. Summer & 0.130 & $* * *$ & 0.018 & -0.438 & $* * *$ & 0.076 & 0.115 & $* * *$ & 0.020 & $0.552^{* * *}$ \\
\hline Precip. Summer Squared & 0.000 & & 0.001 & 0.024 & $* * *$ & 0.004 & 0.002 & $*$ & 0.001 & $-0.022^{* * *}$ \\
\hline Precip. Autumn & 0.145 & $* * *$ & 0.014 & -0.022 & & 0.095 & 0.127 & $* * *$ & 0.015 & 0.149 \\
\hline Precip. Autumn Squared & -0.011 & $* * *$ & 0.001 & 0.002 & & 0.007 & -0.011 & $* * *$ & 0.001 & $-0.014^{*}$ \\
\hline Elevation range & -0.017 & & 0.011 & 0.002 & & 0.036 & -0.011 & & 0.012 & -0.013 \\
\hline Elevation mean & 0.204 & $* * *$ & 0.045 & 0.732 & $* * *$ & 0.176 & 0.018 & & 0.049 & $-0.714^{* * *}$ \\
\hline Subsidies & 0.431 & $* * *$ & 0.016 & -0.003 & & 0.050 & 0.464 & $* * *$ & 0.017 & $0.467^{* * *}$ \\
\hline Distance to ports & -0.900 & $* * *$ & 0.051 & -1.104 & $* * *$ & 0.106 & -0.563 & $* * *$ & 0.072 & $0.541^{* * *}$ \\
\hline Distance to cities & -0.701 & $* * *$ & 0.073 & 0.057 & & 0.178 & -0.953 & $* * *$ & 0.085 & $-1.009^{* * *}$ \\
\hline Population density & 0.498 & $* * *$ & 0.033 & -0.366 & $* *$ & 0.159 & 0.476 & $* * *$ & 0.034 & $0.842^{* * *}$ \\
\hline GDP/inhabitant & 0.003 & $* * *$ & 0.001 & 0.046 & $* * *$ & 0.005 & 0.001 & & 0.001 & $-0.044^{* * *}$ \\
\hline Freight transport & 0.003 & $* * *$ & 0.001 & 0.011 & $* *$ & 0.004 & 0.003 & $* * *$ & 0.001 & -0.007 \\
\hline Rented land & 0.130 & $* * *$ & 0.014 & 0.485 & $* * *$ & 0.023 & -0.084 & $* * *$ & 0.018 & $-0.569^{* * *}$ \\
\hline $\mathrm{pH}$ & 1.191 & $* * *$ & 0.104 & 5.294 & $* * *$ & 0.301 & 0.163 & & 0.121 & $-5.131^{* * *}$ \\
\hline pH squared & -0.075 & $* * *$ & 0.008 & -0.410 & $* * *$ & 0.023 & 0.010 & & 0.010 & $0.42^{* * *}$ \\
\hline Gravel & -0.009 & $* * *$ & 0.003 & 0.022 & $* *$ & 0.009 & -0.037 & $* * *$ & 0.003 & $-0.059^{* * *}$ \\
\hline Silt & -0.013 & $* * *$ & 0.002 & 0.018 & $* * *$ & 0.004 & -0.022 & $* * *$ & 0.002 & $-0.039^{* * *}$ \\
\hline Sand & -0.013 & $* * *$ & 0.001 & 0.004 & $*$ & 0.002 & -0.022 & $* * *$ & 0.001 & $-0.026^{* * *}$ \\
\hline AIC & & & 195204 & & & & & & & 193253.2 \\
\hline BIC & & & 195501 & & & & & & & 193830 \\
\hline $\begin{array}{l}\text { Random effect } \\
\text { countries (Std. Dev) }\end{array}$ & & & 1.397 & & & 0.8347 & & & 1.150 & 1.039 \\
\hline $\begin{array}{l}\text { Random effect } \\
\text { residual (Std. Dev) }\end{array}$ & & & 5.011 & & & 5.0272 & & & 4.875 & 4.922 \\
\hline ICC & & & 0.038 & & & 0.027 & & & 0.053 & \\
\hline Std. Dev (ICC) & & & 0.002 & & & 0.007 & & & 0.003 & \\
\hline Number of farms & & & 60563 & & & 18577 & & & 41986 & 60563 \\
\hline
\end{tabular}

${ }^{* * *} \mathrm{p}<0.01,{ }^{* *} \mathrm{p}<0.05,{ }^{*} \mathrm{p}<0.1$ 
Table 2: Percentage Land Value Marginal Effects at Median Temperature and Precipitation (\%/ha per ${ }^{\circ} \mathrm{C}$ or $\left.\mathrm{cm} / \mathrm{mo}\right) \mathrm{by}$ region

\begin{tabular}{|c|c|c|c|c|c|c|c|c|c|c|c|}
\hline \multirow{4}{*}{$\begin{array}{l}\text { Single Climate- } \\
\text { Response }\end{array}$} & & \multicolumn{5}{|c|}{ Marginal effect of temperature } & \multicolumn{5}{|c|}{ Marginal effect of precipitation } \\
\hline & & Annual & Winter & Spring & Summer & Autumn & Annual & Winter & Spring & Summer & Autumn \\
\hline & East & $0.136 * * *$ & $0.079 * * *$ & $0.516^{* * *}$ & $-0.246 * * *$ & $-0.115^{* * *}$ & $0.079 * * *$ & $0.060 * * *$ & $-0.147 * * *$ & $0.125^{* * *}$ & $0.041^{* * *}$ \\
\hline & West & $0.115^{* * *}$ & $0.054 * * *$ & $0.559 * * *$ & $-0.263 * * *$ & $-0.187 * * *$ & $0.054 * * *$ & $0.064 * * *$ & $-0.128 * * *$ & $0.126^{* * *}$ & $-0.009 * * *$ \\
\hline & East & $0.129 * * *$ & $-0.434 * * *$ & $0.696 * * *$ & $-0.650 * * *$ & $0.518^{* * *}$ & $-0.236 * * *$ & $0.097 * * *$ & $-0.251 * * *$ & $-0.084 * * *$ & $0.001 * * *$ \\
\hline Response & West & $0.122^{* * *}$ & $0.027 * * *$ & $0.541^{* * *}$ & $-0.193 * * *$ & $-0.252 * * *$ & $0.075^{* * *}$ & $0.105^{* * *}$ & $-0.126 * * *$ & $0.133^{* * *}$ & $-0.038 * * *$ \\
\hline
\end{tabular}

Weighted T-test to test whether values significantly different from 0 (i.e., no impact): ${ }^{* * *} \mathrm{p}<0.01,{ }^{* *} \mathrm{p}<0.05,{ }^{*} \mathrm{p}<0.1$.

Table 3: Percentage Land Value Marginal Effects at Median Temperature and Precipitation (\%/ha per $\left.{ }^{\circ} \mathrm{C} \mathrm{or} \mathrm{cm} / \mathrm{mo}\right)$ by country

\begin{tabular}{lrrrr|rrrr} 
& \multicolumn{6}{c|}{ Double Climate-Response } & \multicolumn{5}{|c}{ Single Climate-Response } \\
\cline { 2 - 9 } & $\mathrm{MEt}$ & $\mathrm{R}$ & $\mathrm{MEp}$ & $\mathrm{R}$ & $\mathrm{MEt}$ & $\mathrm{R}$ & $\mathrm{MEp}$ & $\mathrm{R}$ \\
Austria & 0.196 & $(11)$ & 0.112 & $(14)$ & 0.191 & $(13)$ & 0.070 & $(13)$ \\
Belgium & 0.187 & $(10)$ & 0.080 & $(9)$ & 0.173 & $(10)$ & 0.055 & $(8)$ \\
Denmark & 0.154 & $(7)$ & 0.045 & $(3)$ & 0.162 & $(7)$ & 0.016 & $(3)$ \\
Finland & 0.121 & $(5)$ & 0.078 & $(8)$ & 0.140 & $(6)$ & 0.037 & $(6)$ \\
France & 0.149 & $(6)$ & 0.083 & $(12)$ & 0.138 & $(5)$ & 0.064 & $(10)$ \\
Germany & 0.178 & $(9)$ & 0.115 & $(15)$ & 0.169 & $(9)$ & 0.079 & $(15)$ \\
Greece & -0.038 & $(1)$ & 0.080 & $(10)$ & -0.033 & $(1)$ & 0.070 & $(12)$ \\
Ireland & 0.307 & $(15)$ & 0.015 & $(1)$ & 0.276 & $(15)$ & 0.006 & $(1)$ \\
Italy & 0.010 & $(3)$ & 0.050 & $(4)$ & 0.015 & $(3)$ & 0.036 & $(5)$ \\
Luxembourg & 0.200 & $(13)$ & 0.081 & $(11)$ & 0.182 & $(11)$ & 0.059 & $(9)$ \\
Netherlands & 0.197 & $(12)$ & 0.076 & $(7)$ & 0.184 & $(12)$ & 0.047 & $(7)$ \\
Portugal & 0.027 & $(4)$ & 0.063 & $(5)$ & 0.021 & $(4)$ & 0.065 & $(11)$ \\
Spain & -0.005 & $(2)$ & 0.093 & $(13)$ & -0.006 & $(2)$ & 0.078 & $(14)$ \\
Sweden & 0.161 & $(8)$ & 0.070 & $(6)$ & 0.168 & $(8)$ & 0.035 & $(4)$ \\
UK & 0.270 & $(14)$ & 0.027 & $(2)$ & 0.251 & $(14)$ & 0.013 & $(2)$ \\
\hline
\end{tabular}

\begin{tabular}{rrrr|rrrr}
\multicolumn{1}{c}{ Double Climate Response } & \multicolumn{4}{|c}{ Single Climate Response } \\
\hline MEt & $\mathrm{R}$ & MEp & $\mathrm{R}$ & MEt & $\mathrm{R}$ & $\mathrm{MEp}$ & $\mathrm{R}$ \\
-0.137 & $(2)$ & -0.314 & $(1)$ & 0.032 & $(1)$ & 0.100 & $(9)$ \\
0.119 & $(5)$ & -0.209 & $(8)$ & 0.175 & $(9)$ & 0.091 & $(8)$ \\
0.714 & $(10)$ & -0.238 & $(5)$ & 0.129 & $(4)$ & 0.027 & $(2)$ \\
-0.151 & $(1)$ & -0.282 & $(2)$ & 0.110 & $(3)$ & 0.090 & $(7)$ \\
0.474 & $(8)$ & -0.225 & $(7)$ & 0.143 & $(6)$ & 0.044 & $(4)$ \\
0.571 & $(9)$ & -0.238 & $(6)$ & 0.139 & $(5)$ & 0.035 & $(3)$ \\
0.137 & $(6)$ & -0.245 & $(3)$ & 0.159 & $(8)$ & 0.076 & $(5)$ \\
0.019 & $(4)$ & -0.239 & $(4)$ & 0.100 & $(2)$ & 0.102 & $(10)$ \\
0.143 & $(7)$ & -0.131 & $(9)$ & 0.176 & $(10)$ & 0.079 & $(6)$ \\
-0.003 & $(3)$ & 0.148 & $(10)$ & 0.153 & $(7)$ & 0.011 & $(1)$
\end{tabular}

(R) The rank order indicates which countries have the lowest (1) and highest marginal effects.

Bulgaria
Czech Rep
Estonia
Hungary
Latvia
Lithuania
Poland
Romania
Slovakia
Slovenia

Table 4: Percentage change in land value $(\% /$ ha per scenario)

\begin{tabular}{llrr} 
& & NCPNAR & ECHOG \\
\cline { 2 - 4 } Single climate-response & East & 0.029 & 0.214 \\
& West & -0.012 & -0.325 \\
\hline \multirow{2}{*}{ Double climate-response } & East & -0.496 & -0.472 \\
& West & -0.017 & -0.317
\end{tabular}


Figure 1 Percentage change in land value: MEt, and NCPNAR \& ECHOG

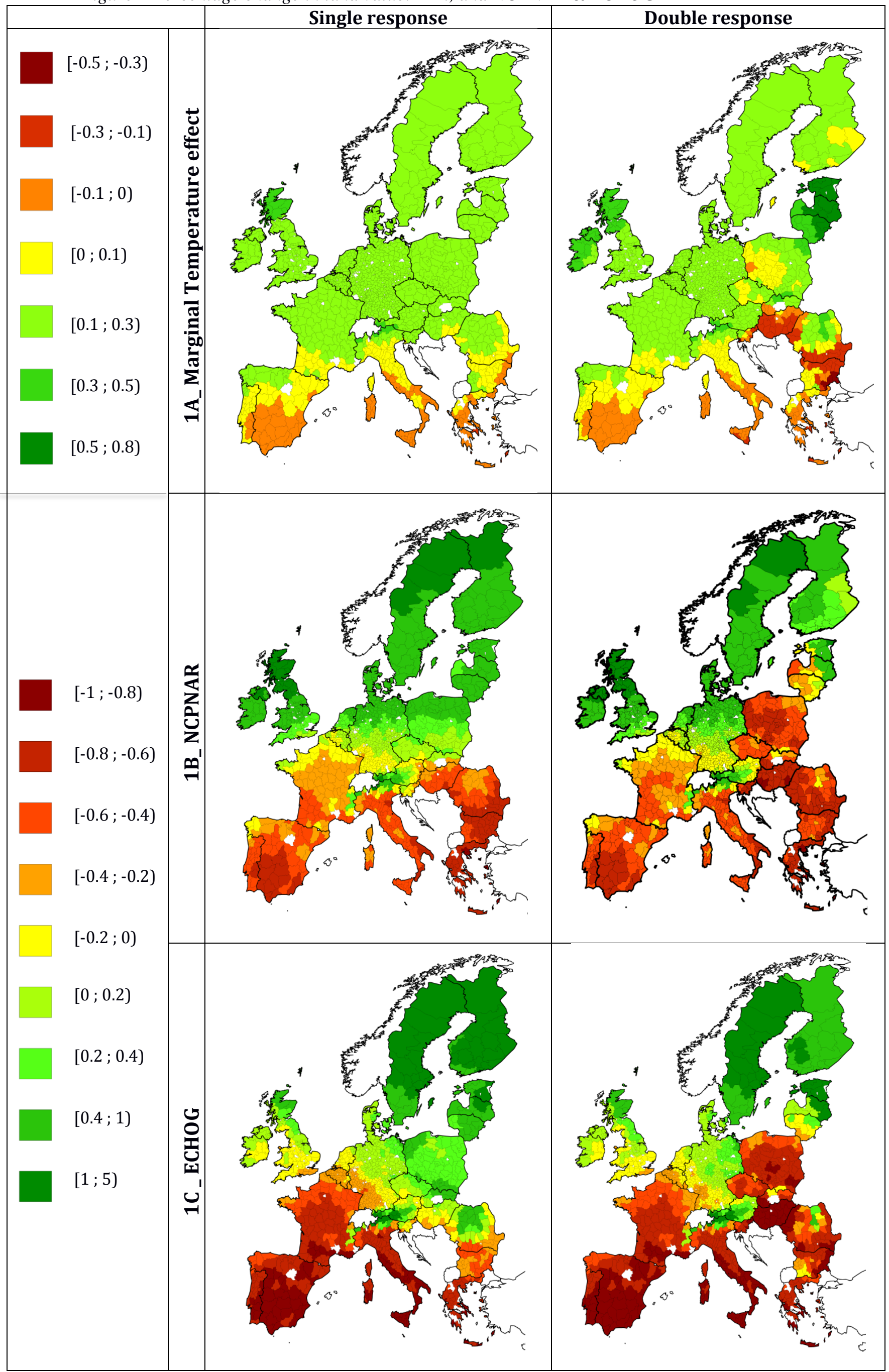


Appendix C: alternative estimation methods

(Intercept)

Temp. Winter

Temp. Winter Squared

Temp. Spring

Temp. Spring Squared

Temp. Summer

Temp. Summer Squared

Temp. Autumn

Temp. Autumn Squared

Precip. Winter

Precip. Winter Squared

Precip. Spring

Precip. Spring Squared

Precip. Summer

Precip. Summer Squared

Precip. Autumn

Precip. Autumn Squared

Elevation range

Elevation mean

Subsidies

Distance to ports

Distance to cities

Population density

GDP/inhabitant

Freight transport

Rented land

$\mathrm{pH}$

pH squared

Gravel

Silt

Sand

Bulgaria

Czech Republic

Estonia

Hungary

Lithuania

Latvia

Poland

Romania

Slovenia

Slovakia

Austria

Belgium

Germany

Denmark

Spain

Finland

France

Greece

Ireland

Italy

Luxembourg

The Netherlands

Portugal

Sweden

United Kingdom

Adjusted $\mathrm{R}^{2}$

AIC

BIC

\begin{tabular}{|c|c|c|c|c|c|c|c|c|c|c|c|}
\hline \multicolumn{6}{|c|}{ OLS Double Climate-Response Model } & \multicolumn{6}{|c|}{ LMEM with ML estimator } \\
\hline \multicolumn{3}{|c|}{ East } & \multicolumn{3}{|c|}{ West } & \multicolumn{3}{|c|}{ East } & \multicolumn{3}{|c|}{ West } \\
\hline Estima & & Std. Error & Estima & & Std. Error & Estima & & Std.Error & Estima & & Std.Error \\
\hline-2.210 & & 2.299 & 2.938 & $* * *$ & 2.350 & -0.977 & & 2.327 & 2.956 & & 2.394 \\
\hline-0.513 & $* * *$ & 0.049 & -0.018 & & 0.021 & -0.511 & $* * *$ & 0.049 & -0.017 & & 0.021 \\
\hline-0.021 & $* *$ & 0.009 & 0.006 & $* * *$ & 0.001 & -0.021 & $* *$ & 0.009 & 0.006 & $* * *$ & 0.001 \\
\hline 1.572 & $* * *$ & 0.142 & 0.082 & $*$ & 0.044 & 1.565 & $* * *$ & 0.141 & 0.082 & * & 0.044 \\
\hline-0.054 & $* * *$ & 0.009 & 0.025 & $* * *$ & 0.002 & -0.054 & $* * *$ & 0.009 & 0.025 & $* * *$ & 0.002 \\
\hline-2.173 & $* * *$ & 0.349 & 0.447 & $* * *$ & 0.075 & -2.140 & $* * *$ & 0.349 & 0.446 & $* * *$ & 0.075 \\
\hline 0.043 & $* * *$ & 0.010 & -0.018 & $* * *$ & 0.002 & 0.042 & $* * *$ & 0.01 & -0.018 & $* * *$ & 0.002 \\
\hline 1.079 & $* * *$ & 0.305 & 0.338 & $* * *$ & 0.069 & 1.064 & $* * *$ & 0.304 & 0.338 & $* * *$ & 0.069 \\
\hline-0.031 & $* *$ & 0.015 & -0.026 & $* * *$ & 0.003 & -0.031 & $* *$ & 0.015 & -0.026 & $* * *$ & 0.003 \\
\hline-0.025 & & 0.116 & 0.109 & $* * *$ & 0.016 & -0.026 & & 0.115 & 0.110 & $* * *$ & 0.016 \\
\hline 0.017 & & 0.013 & 0.000 & & 0.001 & 0.017 & & 0.013 & 0.000 & & 0.001 \\
\hline-0.201 & & 0.136 & -0.200 & $* * *$ & 0.029 & -0.197 & & 0.136 & -0.202 & $* * *$ & 0.029 \\
\hline-0.005 & & 0.012 & 0.006 & $* * *$ & 0.002 & -0.006 & & 0.012 & 0.006 & $* * *$ & 0.002 \\
\hline-0.435 & $* * *$ & 0.076 & 0.113 & $* * *$ & 0.020 & -0.438 & $* * *$ & 0.076 & 0.115 & $* * *$ & 0.02 \\
\hline 0.024 & $* * *$ & 0.004 & 0.002 & $*$ & 0.001 & 0.024 & $* * *$ & 0.004 & 0.002 & * & 0.001 \\
\hline-0.020 & & 0.095 & 0.127 & $* * *$ & 0.015 & -0.022 & & 0.095 & 0.127 & $* * *$ & 0.015 \\
\hline 0.002 & & 0.007 & -0.011 & $* * *$ & 0.001 & 0.002 & & 0.007 & -0.011 & $* * *$ & 0.001 \\
\hline 0.004 & & 0.036 & -0.011 & & 0.012 & 0.002 & & 0.036 & -0.011 & & 0.012 \\
\hline 0.739 & $* * *$ & 0.176 & 0.022 & & 0.049 & 0.732 & $* * *$ & 0.175 & 0.018 & & 0.049 \\
\hline-0.005 & & 0.050 & 0.464 & $* * *$ & 0.017 & -0.003 & & 0.05 & 0.464 & $* * *$ & 0.017 \\
\hline-1.101 & $* * *$ & 0.106 & -0.566 & $* * *$ & 0.072 & -1.104 & $* * *$ & 0.106 & -0.563 & $* * *$ & 0.072 \\
\hline 0.063 & & 0.178 & -0.951 & $* * *$ & 0.085 & 0.056 & & 0.178 & -0.953 & $* * *$ & 0.085 \\
\hline-0.366 & ** & 0.159 & 0.476 & $* * *$ & 0.034 & -0.366 & $* *$ & 0.159 & 0.476 & $* * *$ & 0.034 \\
\hline 0.046 & $* * *$ & 0.005 & 0.001 & & 0.001 & 0.046 & $* * *$ & 0.005 & 0.001 & & 0.001 \\
\hline 0.011 & $* *$ & 0.004 & 0.003 & $* * *$ & 0.001 & 0.011 & $* *$ & 0.004 & 0.003 & $* * *$ & 0.001 \\
\hline 0.485 & $* * *$ & 0.023 & -0.084 & $* * *$ & 0.018 & 0.485 & $* * *$ & 0.023 & -0.084 & $* * *$ & 0.018 \\
\hline 5.301 & $* * *$ & 0.302 & 0.159 & & 0.121 & 5.293 & $* * *$ & 0.301 & 0.163 & & 0.121 \\
\hline-0.411 & $* * *$ & 0.023 & 0.010 & & 0.010 & -0.410 & $* * *$ & 0.023 & 0.010 & & 0.010 \\
\hline 0.022 & $* *$ & 0.009 & -0.037 & $* * *$ & 0.003 & 0.022 & $* *$ & 0.009 & -0.037 & $* * *$ & 0.003 \\
\hline 0.018 & $* * *$ & 0.004 & -0.022 & $* * *$ & 0.002 & 0.017 & $* * *$ & 0.004 & -0.022 & $* * *$ & 0.002 \\
\hline 0.004 & $* *$ & 0.002 & -0.022 & $* * *$ & 0.001 & 0.004 & $*$ & 0.002 & -0.022 & $* * *$ & 0.001 \\
\hline 1.166 & $* * *$ & 0.110 & & & & & & & & & \\
\hline 1.388 & $* * *$ & 0.079 & & & & & & & & & \\
\hline 2.138 & $* * *$ & 0.137 & & & & & & & & & \\
\hline 1.213 & $* * *$ & 0.074 & & & & & & & & & \\
\hline 1.592 & $* * *$ & 0.090 & & & & & & & & & \\
\hline 1.696 & $* * *$ & 0.106 & & & & & & & & & \\
\hline 1.717 & $* * *$ & 0.084 & & & & & & & & & \\
\hline 0.060 & & 0.087 & & & & & & & & & \\
\hline $\begin{array}{l}2.740 \\
\quad \text { (omi }\end{array}$ & $\begin{array}{l}* * * \\
\text { tted) }\end{array}$ & 0.150 & & & & & & & & & \\
\hline & & & -2.450 & $* * *$ & 0.053 & & & & & & \\
\hline & & & 0.183 & $* * *$ & 0.052 & & & & & & \\
\hline & & & 0.134 & $* * *$ & 0.037 & & & & & & \\
\hline & & & 1.436 & $* * *$ & 0.047 & & & & & & \\
\hline & & & -0.205 & $* * *$ & 0.054 & & & & & & \\
\hline & & & 0.393 & $* * *$ & 0.090 & & & & & & \\
\hline & & & -0.946 & $* * *$ & 0.040 & & & & & & \\
\hline & & & 0.496 & $* * *$ & 0.073 & & & & & & \\
\hline & & & 0.948 & $* * *$ & 0.032 & & & & & & \\
\hline & & & 1.087 & $* * *$ & 0.052 & & & & & & \\
\hline & & & -0.396 & $* * *$ & 0.069 & & & & & & \\
\hline & & & 1.120 & $* * *$ & 0.039 & & & & & & \\
\hline & & & -2.275 & $* * *$ & 0.066 & & & & & & \\
\hline & & & $\begin{array}{r}0.667 \\
\quad \text { (omi }\end{array}$ & $\begin{array}{l}* * * \\
\text { tted) }\end{array}$ & 0.060 & & & & & & \\
\hline \multicolumn{12}{|c|}{0.7532} \\
\hline & & & & & & & & 193,3 & & & \\
\hline
\end{tabular}

${ }^{* * *} \mathrm{p}<0.01,{ }^{* *} \mathrm{p}<0.05,{ }^{*} \mathrm{p}<0.1$ 


\section{References}

Carter, T.R. and La Rovere, E.L., 2001. Developing and Applying Scearnios. Climate Change 2001: Impacts, Adaptation and Vulnerability. J. J. McCarthy, O. F. Canziani, N. A. Leary, D. J. Dokken and K. S. White. Cambridge, UK, pp. 145-190.

Chen, Y., Wu, Z., Okamoto, K., Han, X., Ma, G., Chien, H. and Zhao, J., 2013. The impacts of climate change on crops in China: A Ricardian analysis. Global and Planetary Change 104, pp. 61-74.

Ciaian, P., Kancs, A., Swinnen, J., Van Herck, K. and Vrancken, L., 2012. Key Issues and Developments in Farmland Rental Markets in EU Member States and Candidate Countries Comparative Analysis of Factor Markets for Agriculture across the Member States. Brussels, Centre for European Policy Studies.

Cline, W.R., 2007. Global warming and agriculture: Impact estimates by country. Peterson Institute.

Crawley, M.J., 2007. The R Book. Wiley.

Downing, T.E., Ringius, L., Hulme, M. and Waughray, D., 1997. Adapting to climate change in Africa., in: (Eds), Mitigation and Adaptation Strategies for Global Change 2. Kluwer Academic Publishers, Belgium, pp. 19-44.

ECB, 2016. Euro exchange rates USD. Available from: https://www.ecb.europa.eu/stats/exchange/eurofxref/html/eurofxref-graph-usd.en.html. Iaccessed 13.08.2016).

Erjavec, E., 2012. Why no "Green Revolution" in new Member States? CAP Reform.eu.

ESRI, 2014. Homepage ESRI. Available from: http://www.esri.com/.

EuroGeographics, 2014. Homepage EuroGeographics. Available from: http://www.eurogeographics.org/.

European Commision, 2014. CAP context indicators 2014-2020. 28. Gross Fixed Capital Formation in Agriculure.

Eurostat, 2016. Database. E. Commision.

FADN, 2014. FADN Homepage. Available from: http://ec.europa.eu/agriculture/rica/.

FAO/IIASA/ISRIC/ISSCAS/JRC, 2009. Harmonized World Soil Database Version 1.1. FAO, Rome, Italy and IIASA, Laxenburg, Austria.

Fay, M., Block, R. and Ebinger, J., 2010. Aapting to Climate Change in Eastern Europe and Centarl Asia, World Bank.

Fisher, A.C., Hanemann, W.M., Roberts, M.J. and Schlenker, W., 2012. The Economic Impacts of Climate Change: Evidence from Agricultural Output and Random Fluctuations in Weather: Comment. American Economic Review 102 (7), pp. 3749-3760.

Giannakis, E. and Bruggeman, A., 2015. The highly variable economic performance of European agriculture. Land Use Policy 45, pp. 26-35.

Goodess, C., 2014. Climate change scenarios. University of East Anglia, Available from: http://www.cru.uea.ac.uk/information-sheets. 
Haddad, B.M., 2005. Ranking the adaptive capacity of nations to climate change when socio-political goals are explicit. Global Environmental Change 15 (2), pp. 165-176.

IPCC, 2001. Climate Change 2001: Working Group II: Impacts, Adaptation and Vulnerability, Summary for Policymakers. New York, Cambridge University Press.

IPCC, 2014d. Summary for policymakers, in: C. B. Field, V. R. Barros, D. J. Dokken, K. J. Mach, M. D. Mastrandrea, T. E. Bilir, M. Chatterjee, K. L. Ebi, Y. O. Estrada, R. C. Genova, B. Girma, E. S. Kissel, A. N. Levy, S. MacCracken, P. R. Mastrandrea and L. L. White (Eds), Climate Change 2014: Impacts,Adaptation, and Vulnerability. Part A: Global and Sectoral Aspects. Contribution of Working Group II to the Fifth Assessment Report of the Intergovernmental Panel on Climate Change. Cambridge University Press, Cambridge, United Kingdom and New York, NY, USA, pp. 1-32.

Kelly, D.L., Kolstad, C.D. and Mitchell, G.T., 2005. Adjustment costs from environmental change. Journal of Environmental Economics and Management 50 (3), pp. 468-495.

Larget, B., Random Effects in R Statistics 572 (2007),

Legutke, S. and Voss, R., 1999. The Hamburg Atmosphere-Ocean Coupled Circulation Model ECHO-G Technical report. Hamburg, German Climate Computer Centre (DKRZ). 18, pp. 62.

Lippert, C., Krimly, T. and Aurbacher, J., 2009. A Ricardian analysis of the impact of climate change on agriculture in Germany. Climatic Change 97 (3-4), pp. 593-610.

Maharjan, K.L. and Joshi, N.P., 2013. Climate Change, Agriculture and Rural Livelihoods in Developing Countries. Springer, Japan.

Massetti, E. and Mendelsohn, R., 2011b. The impact of climate change on U.S. agriculture: a repeated cross-sectional Ricardian analysis., in: A. Dinar and R. Mendelsohn (Eds), Handbook on Climate Change and Agriculture. Cheltenham, UK, Northhampton, MA, USA.

Mendelsohn, R., 2007. Measuring Climate Impacts With Cross-Sectional Analysis. Climatic Change 81 (1), pp. 1-7.

Mendelsohn, R., Arellano-Gonzalez, J. and Christensen, P., 2009. A Ricardian analysis of Mexican farms. Environment and Development Economics 15, pp. 153-171.

Mendelsohn, R. and Dinar, A., 2003. Climate, Water, and Agriculture. Land Economics 79 (3), pp. 328341.

Mendelsohn, R., Nordhaus, W.D. and Shaw, D., 1994. The impact of Global Wamring on Agriculture: a Ricardian Analysis. American Economic Review 84 (4), pp. 753-771.

Mendelsohn, R. and Reinsborough, M., 2007. A Ricardian analysis of US and Canadian farmland. Climatic Change 81, pp. 9-17.

Nakicenovic, N., Alcamo, J., Davis, G., de Vries, B., Fenhann, J., Gaffin, S., Gregory, K., Grübler, A., Yong Jung, T.Y., Kram, T., Lebre La Rovere, E., Michaelis, L., Mori, S., Morita, T., Pepper, W., Pitcher, H., Price, L., Riahi, K., Roehrl, A., Rogner, H.H., Sankovski, A., Schlesinger, M., Shukla, P., Smith, S., Swart, R., van Rooijen, S., Victor, N. and Dadi, Z., 2000. Special Report on Emissions Scenarios: A Special Report of Working Group III of the Intergovernmental Panel on Climate Change. Cambridge, UK.

National Geospatial-Intelligence Agency, 2014. World port index Available from: http://msi.nga.mil/NGAPortal/MSI.portal? nfpb=true\& pageLabel=msi portal page 62\&pubCode=0015.

Natural Earth, 2014. Natural Earth Data Homepage. Available from: http://www.naturalearthdata.com/. 
New, M., Lister, D., Hulme, M. and Makin, I., 2002. A high-resolution data set of surface climate over global land areas. Climate reserach 21 (1), pp. 1-25.

Polsky, C. and Easterling III, W.E., 2001. Adaptation to climate variability and change in the US Great Plains:: A multi-scale analysis of Ricardian climate sensitivities. Agriculture, Ecosystems \& Environment 85 (1-3), pp. 133-144.

R Core Team, 2014. R: A Language and Environment for Statistical Computing. Vienna, Austria, R Foundation for Statistical Computing.

Ricardo, D., 1817. On the Principles of Political Economy and Taxation. Cambridge University Press.

Sanghi, A. and Mendelsohn, R., 2008. The impacts of global warming on farmers in Brazil and India. Global Environmental Change 18 (4), pp. 655-665.

Schlenker, W., Hanemann, W.M. and Fisher, A.C., 2006. The impact of global warming on U.S. agriculture: an econometric analysis of optimal growing conditions. . Review of Economics and Statistics 88 (1), pp. 113-125.

Schmid, E., Sinabell, F. and Hofreither, M.F., 2007. Phasing out of environmentally harmful subsidies: Consequences of the 2003 CAP reform. Ecological Economics 60 (3), pp. 596-604.

Seo, S.N. and Mendelsohn, R., 2008a. A Ricardian Analysis fo the impact of climate change on south american farms. Chilean journal of agricultural research 68 (1), pp. 69-79.

Smit, B. and Wandel, J., 2006. Adaptation, adaptive capacity and vulnerability. Global Environmental Change 16 (3), pp. 282-292.

Supit, I., van Diepen, C.A., de Wit, A.J.W., Kabat, P., Baruth, B. and Ludwig, F., 2010. Recent changes in the climatic yield potential of various crops in Europe. Agricultural Systems 103 (9), pp. 683-694.

Swinnen, J.F.M. and Vranken, L., 2009. Land \& EU Accession. Review of the transitional restrictions by new member states on the acquisition of agricultural real estate. Brussels, Centre for European Policy Studies.

Timmins, C., 2006. Endogenous Land use and the Ricardian Valuation of Climate Change. Environmental and Resource Economics 33 (1), pp. 119-142.

Tol, R.S.J., Downing, T.E., Kuik, O.J. and Smith, J.B., 2004. Distributional aspects of climate change impacts. Global Environmental Change 14, pp. 259-272.

UNEP, 2014. The Adaptation Gap Report 2014. Nairobi, United Nations Environment Programme (UNEP).

Van Passel, S., Massetti, E. and Mendelsohn, R., 2016. A Ricardian Analysis of the Impact of Climate Change on European Agriculture. Environmental and Resource Economics, pp. 1-36.

Vincent, K., 2007. Uncertainty in adaptive capacity and the importance of scale. Global Environmental Change 17 (1), pp. 12-24.

Wang, J., Mendelsohn, R., Dinar, A., Huang, J., Rozelle, S. and Zhang, L., 2009. The impact of climate change on China's agriculture. Agricultural Economics 40, pp. 323-337.

Washington, W.M., Weatherly, J.W., Meehl, G.A., Semtner Jr., A.J., Bettge, T.W., Craig, A.P., Strand Jr., W.G., Arblaster, J.M., Wayland, V.B., James, R. and Zhang, Y., 2000. Parallel climate model (PCM) 
control and transient simulations. Clim. Dyn. 16, pp. 755-774.

Zuur, A.F., Ieno, E.N., Walker, N.J., Saveliev, A.A. and Smith, G.M., 2009. Mixed Effects Models and Extensions in Ecology with R. Springer, New York. 